\title{
Simple Pretreatment Method for Tritium Measurement in Environmental Water Samples using a Liquid Scintillation Counter*)
}

\author{
Shunya NAKASONE, Sumi YOKOYAMA ${ }^{1)}$, Tomoyuki TAKAHASHI ${ }^{2)}$, Masakazu OTA ${ }^{3)}$, \\ Hideki KAKIUCHI $^{4}$, Shinji SUGIHARA ${ }^{5)}$, Shigekazu HIRAO ${ }^{6}$, Noriyuki MOMOSHIMA ${ }^{7}$, \\ Toshiya TAMARI ${ }^{7)}$, Nagayoshi SHIMA ${ }^{7)}$, Mariko ATARASHI-ANDOH ${ }^{3)}$, Satoshi FUKUTANI ${ }^{2)}$, \\ Kaori NAKAMURA, Akinobu ISHIMINE ${ }^{4}$, Masahide FURUKAWA, Masahiro TANAKA ${ }^{8,9)}$ \\ and Naofumi AKATA ${ }^{10)}$ \\ University of the Ryukyus, 1 Senbaru, Nishihara-cho, Nakagami-gun, Okinawa 903-0213, Japan \\ ${ }^{1)}$ Fujita Health University, 1-98 Dengakugakubo, Kutsukake-cho, Toyoake, Aichi 470-1192, Japan \\ ${ }^{2)}$ Kyoto University, 2 Asashiro-Nishi, Kumatori-cho, Sennan-gun, Osaka 590-0494, Japan \\ 3) Japan Atomic Energy Agency, 2-4 Shirakata, Tokai-mura, Naka-gun, Ibaraki 319-1195, Japan \\ 4) Institute for Environmental Sciences, 1-7 Ienomae, Obuchi, Rokkasho-mura, Kamikita-gun, Aomori 039-3212, Japan \\ ${ }^{5)}$ Kyushu University, 744 Motooka, Nishi-ku, Fukuoka 819-0395, Japan \\ ${ }^{6)}$ Institute of Environment Radioactivity, Fukushima University, 1 Kanayagawa, Fukushima, \\ Fukushima 960-1296, Japan \\ 7) Kyushu Environmental Evaluation Association, 1-10-1 Matsukadai, Higashi-ku, Fukuoka, Fukuoka 813-0004, Japan \\ ${ }^{8)}$ National Institute for Fusion Science, National Institutes of Natural Sciences, 322-6 Oroshi-cho, Toki, \\ Gifu 509-5292, Japan \\ ${ }^{9)}$ The Graduate University for Advanced Studies, SOKENDAI, 322-6 Oroshi-cho, Toki, Gifu 509-5292, Japan \\ ${ }^{10)}$ Institute of Radiation Emergency Medicine, Hirosaki University, 66-1 Hon-cho, Hirosaki, Aomori 036-8564, Japan
}

(Received 16 November 2020 / Accepted 1 February 2021)

The aim of this study is to evaluate quantitatively the effectiveness of the ion exchange resins and activated carbon in tritium measurement. A standard water sample was adjusted to a tritium concentration of $5 \mathrm{~Bq} \mathrm{~L}^{-1}$. This sample was stirred with the cation exchange $(\mathrm{PCH})$ and anion exchange (PAO) resins and activated carbon. After stirring the samples, the supernatant in each sample was filtered through $0.45 \mu \mathrm{m}$ membrane filters. The electrical conductivity in an experimental condition, where the amounts of $\mathrm{PCH}, \mathrm{PAO}$, and activated carbon were $0.3 \mathrm{~g}, 0.3 \mathrm{~g}$, and $0.6 \mathrm{~g}$, respectively, was lower than that of the sample treated by the distillation method. The distillation method requires approximately $12 \mathrm{~h}$ to process; however, the same level of results was achieved in $5 \mathrm{~min}$. The tritium concentration in each experiment was within the standard deviation. These results suggested that proposed batch method involving ion exchange resins and activated carbon had negligible effect on tritium measurement. The ion concentration and the total organic carbon for the samples were decreased in 5 min. These results demonstrate the effectiveness of the impurity removal from the sample water by ion exchange resins.

(c) 2021 The Japan Society of Plasma Science and Nuclear Fusion Research

Keywords: environmental tritium analysis, rapid pretreatment method, ion exchange resin, activated carbon, batch method, liquid scintillation counting, ion chromatography, total organic carbon analysis

DOI: $10.1585 /$ pfr. 16.2405035

\section{Introduction}

Tritium $\left({ }^{3} \mathrm{H}\right)$ is a radioisotope of hydrogen that decays into ${ }^{3} \mathrm{He}$ with a half-life of 12.32 years. Most of the environmental tritium is produced by the nuclear interactions of cosmic rays with nitrogen and oxygen atoms in the upper atmosphere [1]. Meanwhile, significant quantities of anthropogenic tritium were released into the environment by nuclear weapon tests in the early 1960s [2]. Therefore,

author'se-mail:k198602@eve.u-ryukyu.ac.jp

*) This article is based on the presentation at the 29th International Toki Conference on Plasma and Fusion Research (ITC29). the tritium concentration of precipitation rapidly increased to approximately 200 times that of the background level in this era [2]. Tritium concentrations in precipitation were gradually decreased after the acceptance of the Partial Test Ban Treaty (PTBT) in 1963 [3]. In recent years, nuclear facilities such as nuclear power reactors and nuclear fuel reprocessing plants have released tritium to the environment, thus becoming the main sources of anthropogenic tritium. Furthermore, in March 2011, tritium was released into the environment along with various other radionuclides from the Fukushima Daiichi Nuclear Power Plant by the huge 
accident. Thereafter, in the Fukushima Daiichi Nuclear Power Plant, contaminated water, i.e., water containing tritium, was stored and treated in large quantities. After dilution, the tritiated water would be discharged into the ocean. This disposal may concern for its impact on the marine environment. Therefore, the monitoring of environmental tritium is essential. Additionally, in the future, nuclear fusion reactors will require large amount of tritium for use as fuel. Considering steady releases from the fusion facilities and the unexpected releases such as those in the case of accidents, environmental tritium monitoring is extremely important. In particular, improved modeling and analytical methods to understand the environmental behaviors, must be improved. In order to realize rapid tritium analysis as required for environmental monitoring and radiation screening, it is necessary to consider the pretreatment method. In general, removing impurities such as organic matter and other types of dissolved matter from environmental water samples is necessary to reduce the chemical quenching for a highly precise tritium analysis using the liquid scintillation counting method [4]. Distillation is a conventional pretreatment method used in tritium analysis of environmental water samples; however, this method is complicated and involves a time-consuming process requiring $24 \mathrm{~h}$ to remove impurities from $1 \mathrm{~L}$ of water. Therefore, we have proposed and developed a new measurement development for the analysis of tritium in the environmental samples [5]. In the previous study, the rapid pretreatment method to remove impurities including dissolved ions and organic matter using ion exchange resins and activated carbon was evaluated [6]. These results demonstrated the effectiveness of impurity removal from the sample water using ion exchange resins. Moreover, the study confirmed that such an effect can be achieved over a short time, i.e., in $5 \mathrm{~min}$.

In the previous study, we have measured only basic parameters ( $\mathrm{pH}$, electrical conductivity, and absorption spectra) as a preliminary experiment. However, the removal performance of ion exchange resin and activated carbon was insufficiently discussed. Two issues remain in applying this method to pretreatment for tritium analysis: 1) an evaluation of the effect of the proposed method on the tritium concentration, 2) a quantitative understanding of the removal of impurities using ion exchange resins and activated carbon. Therefore, the aim of this study is to evaluate quantitatively the effectiveness of the ion exchange resins and activated carbon. In this study, the tritium concentration in the pretreated sample was measured. Moreover, the amounts of dissolved ions and dissolved organic matter were measured, with an emphasis on impurity removal.

\section{Materials and Methods}

\subsection{Samples and chemical reagents}

In this study, a standard water sample was prepared by mixing concentrated $\mathrm{D}_{2} \mathrm{O}$ water $\left(34.0 \pm 1.7 \mathrm{BqL}^{-1}\right)$ and river water. The river water was collected from the Houe River $\left(26^{\circ} 8,12.38^{\prime \prime} \mathrm{N}, 127^{\circ} 41,11.45^{\prime \prime} \mathrm{E}\right)$ in Okinawa, Japan. The standard water sample was adjusted to approximately $5 \mathrm{~Bq} \mathrm{~L}^{-1}$.

Powdex resins (cation exchange resin: $\mathrm{PCH}$, anion exchange resin: PAO, Graver Technologies, USA) in the form of powder beads and activated carbon (GW 10/32, AS ONE, Japan) were used in this study. The exchange capacities of PCH and PAO were 4.8 and 4.0 meq dry $\mathrm{g}^{-1}$, respectively. The ion exchange resins removed dissolved ions while the activated carbon removed organic and other types of dissolved matter from the standard water sample.

\subsection{Experimental procedure}

We conducted the following three experiments that differed in terms of the amounts of ion exchange resins and activated carbon used; Experiment-1: $0.1 \mathrm{~g}, 0.1 \mathrm{~g}$, and $0.2 \mathrm{~g}$ of $\mathrm{PCH}, \mathrm{PAO}$, and activated carbon respectively; Experiment-2: $0.2 \mathrm{~g}, 0.2 \mathrm{~g}$, and $0.4 \mathrm{~g}$, respectively; and Experiment-3: $0.3 \mathrm{~g}, 0.3 \mathrm{~g}$, and $0.6 \mathrm{~g}$, respectively. Additionally, the stirring times were varied from 5, to 10, 20, and $30 \mathrm{~min}$ in each experimental composition set. Three $100 \mathrm{~mL}$ samples were prepared for each condition $(\mathrm{n}=3)$. The pretreatment by ion exchange resins and activated carbon is also referred to as "batch treatment" in the subsequent sections of the paper.

The PCH and PAO were first pretreated with deionized distilled water using a stirring machine (RS-4DN, AS ONE, Japan) at $100 \mathrm{rpm}$ for $5 \mathrm{~min}$. Then, standard water samples of $100 \mathrm{~mL}$ were mixed with the ion exchange resins and activated carbon, and the mixtures were stirred at $1000 \mathrm{rpm}$. After stirring the samples, the supernatant from each sample was filtered through $0.45 \mu \mathrm{m}$ membrane filters (25CS, ADVANTEC, USA). This was used as the sample for measurement. Finally, the samples $\mathrm{pH}$ and electrical conductivity (EC) were measured using a LAQUAtwin-pH-11B meter (HORIBA, Japan) and B-771COND meter (HORIBA, Japan), respectively. In addition, $50 \mathrm{~mL}$ of each sample was mixed with the same volume of a liquid scintillation cocktail (Ultima Gold LLT, PerkinElmer, USA), and the tritium concentration was measured with a low background liquid scintillation counter (LBC-LB-7, Hitachi, Japan) for 1000 min per sample. To evaluate quantitatively the effectiveness of the impurities removal, the absorption spectra in the ultravioletvisible (UV) range were obtained using a single-beam UV light spectrophotometer (ASUV-3100PC, Japan). Ion chromatography analysis (ICS-1600, Japan) and total organic carbon (TOC) analyses (TOC-L CPH, Japan) were also conducted for each sample.

\section{Results and Discussion}

The experimental results of physical and chemical parameters of water samples are summarized in Table 1 . The 
Table 1 Physical and chemical parameters of water samples measured in Experiment-1, Experiment-2, and Experiment-3 using the batch method.

\begin{tabular}{|c|c|c|c|c|c|c|c|c|c|c|c|c|c|c|c|c|c|c|c|c|c|c|c|c|}
\hline & \multicolumn{3}{|c|}{$\mathrm{pH}$} & \multicolumn{3}{|c|}{$\mathrm{EC}\left(\mathrm{mS} \mathrm{m}^{-1}\right)$} & \multicolumn{3}{|c|}{${ }^{3} \mathrm{H}\left(\mathrm{Bq} \mathrm{L}{ }^{-1}\right)$} & \multicolumn{3}{|c|}{ SQP } & \multicolumn{3}{|c|}{ TOC $\left(\mathrm{mg} \mathrm{L}^{-1}\right)$} & \multicolumn{8}{|c|}{ Ion concentration $\left(\mathrm{mg} \mathrm{L}^{-1}\right)$} \\
\hline & & Ave. & \pm & S.D. & Ave. & \pm & S.D. & Ave. & \pm & S.D. & Ave. & \pm & S.D. & Ave. & \pm & S.D. & $\mathrm{Na}^{+}$ & $\mathrm{NH}_{4}{ }^{+}$ & $\mathrm{K}^{+}$ & $\mathrm{Mg}^{2+}$ & $\mathrm{Ca}^{2+}$ & $\mathrm{Cl}^{-}$ & $\mathrm{NO}_{3}^{-}$ & $\mathrm{SO}_{4}{ }^{2}$ \\
\hline Standard sa & ample & 7.8 & \pm & 0.1 & 75.7 & \pm & 0.5 & 4.80 & \pm & 0.08 & 789.8 & \pm & 0.9 & 1.98 & \pm & 0.09 & 34.8 & - & 10.3 & 10.6 & 96.4 & 50.7 & 21.7 & 60.4 \\
\hline \multicolumn{2}{|c|}{ Distillation } & 5.6 & \pm & 0.2 & 15.1 & \pm & 0.9 & 4.86 & \pm & 0.39 & 788.3 & \pm & 5.3 & 0.20 & \pm & 0.17 & 0.28 & 3.2 & 0.16 & - & - & 0.31 & 0.55 & - \\
\hline \multirow[t]{4}{*}{ Experiment-1 } & $5 \mathrm{~min}$ & 7.3 & \pm & 0.0 & 52.3 & \pm & 2.1 & 4.48 & \pm & 0.16 & 791.3 & \pm & 2.1 & 1.16 & \pm & 0.07 & 33.0 & 1.4 & 9.5 & 8.5 & 48.9 & 35.6 & 8.1 & 8.2 \\
\hline & $10 \mathrm{~min}$ & 7.3 & \pm & 0.0 & 50.9 & \pm & 0.2 & 4.65 & \pm & 0.27 & 789.8 & \pm & 1.8 & 0.87 & \pm & 0.11 & 33.4 & 2.4 & 10.1 & 8.8 & 49.7 & 36.2 & 7.8 & 7.2 \\
\hline & $20 \mathrm{~min}$ & 7.4 & \pm & 0.0 & 52.7 & \pm & 1.2 & 4.34 & \pm & 0.50 & 783.1 & \pm & 1.1 & 0.73 & \pm & 0.08 & 29.9 & 2.6 & 7.9 & 7.8 & 44.3 & 31.5 & 6.5 & 5.5 \\
\hline & $30 \mathrm{~min}$ & 7.4 & \pm & 0.0 & 51.4 & \pm & 0.4 & 4.56 & \pm & 0.34 & 789.4 & \pm & 0.5 & 0.59 & \pm & 0.12 & 31.0 & 2.8 & 8.3 & 8.0 & 44.9 & 33.1 & 6.7 & 5.7 \\
\hline \multirow[t]{4}{*}{ Experiment-2 } & $5 \mathrm{~min}$ & 6.8 & \pm & 0.1 & 29.0 & \pm & 1.0 & 4.32 & \pm & 0.18 & 789.3 & \pm & 0.6 & 0.82 & \pm & 0.09 & 27.9 & 2.2 & 7.9 & 2.4 & 13.0 & 14.5 & 2.0 & 0.5 \\
\hline & $10 \mathrm{~min}$ & 6.9 & \pm & 0.0 & 31.3 & \pm & 0.6 & 4.97 & \pm & 0.43 & 787.5 & \pm & 2.8 & 0.68 & \pm & 0.02 & 31.9 & 2.5 & 9.1 & 3.7 & 17.8 & 18.3 & 2.5 & 0.9 \\
\hline & $20 \mathrm{~min}$ & 6.9 & \pm & 0.1 & 26.6 & \pm & 3.1 & 4.44 & \pm & 0.49 & 784.0 & \pm & 5.2 & 0.50 & \pm & 0.09 & 28.6 & 3.1 & 7.5 & 3.0 & 13.9 & 14.9 & 1.9 & 0.5 \\
\hline & $30 \mathrm{~min}$ & 6.9 & \pm & 0.1 & 29.8 & \pm & 2.3 & 5.55 & \pm & 0.40 & 788.4 & \pm & 0.5 & 0.67 & \pm & 0.08 & 30.9 & 2.9 & 7.6 & 2.7 & 11.8 & 14.9 & 1.8 & 0.4 \\
\hline \multirow{4}{*}{ Experiment-3 } & $5 \mathrm{~min}$ & 6.1 & \pm & 0.1 & 6.7 & \pm & 0.3 & 4.79 & \pm & 0.05 & 788.8 & \pm & 6.2 & 1.03 & \pm & 0.56 & 10.4 & 0.69 & 2.5 & - & & 3.6 & 0.5 & - \\
\hline & $10 \mathrm{~min}$ & 6.0 & \pm & 0.1 & 4.7 & \pm & 0.7 & 3.85 & \pm & 0.43 & 784.6 & \pm & 2.7 & 1.68 & \pm & 0.57 & 7.6 & 0.60 & 1.7 & - & $\begin{array}{ll}- \\
-\end{array}$ & 2.0 & 0.3 & - \\
\hline & $20 \mathrm{~min}$ & 6.1 & \pm & 0.2 & 4.7 & \pm & 2.3 & 5.15 & \pm & 0.46 & 788.4 & \pm & 3.0 & 1.64 & \pm & 0.60 & 6.8 & 0.80 & 1.4 & - & - & 1.7 & 0.2 & - \\
\hline & $30 \mathrm{~min}$ & 5.9 & \pm & 0.1 & 2.9 & \pm & 0.6 & 4.43 & \pm & 0.20 & 787.6 & \pm & 1.6 & 2.10 & \pm & 0.01 & 6.5 & 0.59 & 1.0 & - & - & 1.7 & 0.2 & - \\
\hline
\end{tabular}

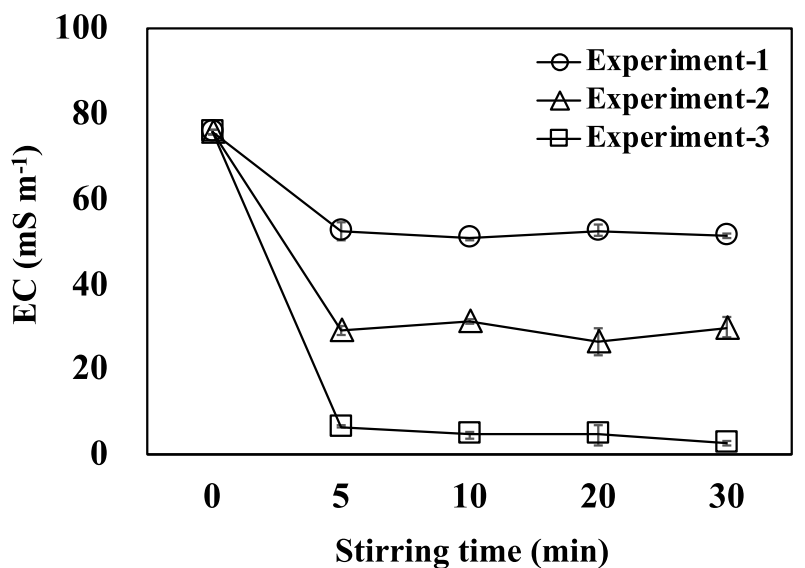

Fig. 1 Change in EC with respect to stirring time in the water samples from each experiment.

results of each parameter are shown below.

\subsection{The change in $\mathrm{EC}$ and $\mathrm{pH}$ for each ex- periment}

From results of the Table 1, the changes in EC in the water samples as the function of stirring time are shown in Fig. 1. The EC decreased with stirring time for $5 \mathrm{~min}$. In the case of Experiment-3, the EC decreased to $6.7 \mathrm{mS} \mathrm{m}^{-1}$ over $5 \mathrm{~min}$ stirring. The tritium analysis manual specifies that the EC after pretreatment should be less than $1 \mathrm{mS} \mathrm{m}^{-1}$, equal to that of pure water [4]. In these experiments, an EC value of less than $1 \mathrm{mS} \mathrm{m}^{-1}$ was not achieved, however, the EC in Experiment-3 was lower than that of the sample pretreated by the distillation method. The distillation method requires approximately $12 \mathrm{~h}$, however, Experiment-3 achieved the same results within $5 \mathrm{~min}$. Hence, the results showed that a significant time reduction was possible using the ion exchange resin method.

Figure 2 shows the changes in $\mathrm{pH}$ in the water samples as the function of stirring time from each experiment. The $\mathrm{pH}$ was decreasing of over $5 \mathrm{~min}$. However, after $10 \mathrm{~min}$, the $\mathrm{pH}$ remained stable with further stirring in each experiment. The decreasing $\mathrm{pH}$ suggested that an active reaction between the ion exchange resins and dissolved ions

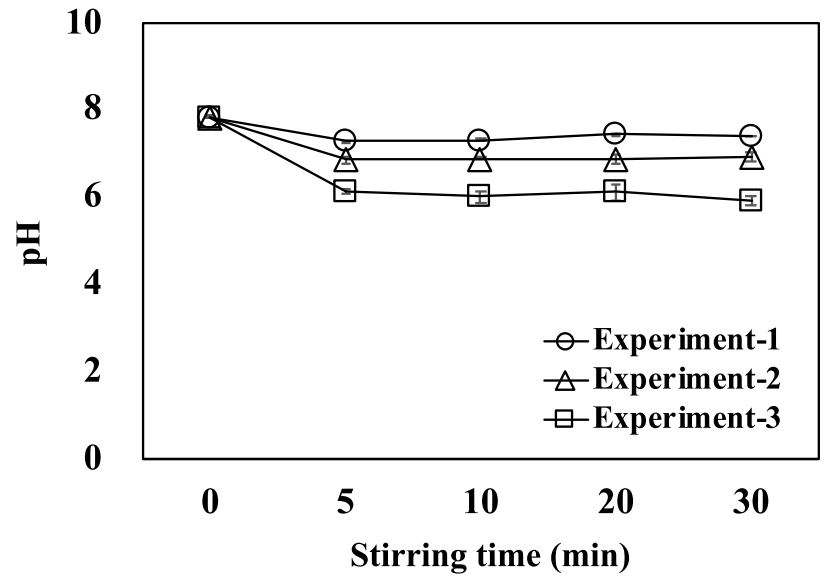

Fig. 2 Change in $\mathrm{pH}$ with increasing stirring time in the water samples from each experiment.

occurred in the first $5 \mathrm{~min}$.

\subsection{Tritium measurement in water samples}

The arithmetic mean \pm standard deviation of the tritium concentrations for the standard water samples and the distillation treated samples were estimated to be $4.80 \pm 0.08 \mathrm{~Bq} \mathrm{~L}^{-1}$ and $4.86 \pm 0.39 \mathrm{~Bq} \mathrm{~L}^{-1}$, respectively. In each experiment, no significant change in tritium concentration with stirring time was observed. In the batch treatment experiments over $5 \mathrm{~min}$ stirring, the tritium concentrations in the Experiment-1, -2 , and -3 samples ranged from $4.48 \pm 0.16 \mathrm{BqL}^{-1}, 4.32 \pm 0.18 \mathrm{BqL}^{-1}$, and $4.79 \pm 0.05 \mathrm{~Bq} \mathrm{~L}^{-1}$, respectively. Based on the results of the spectral quench parameter (SQP), the standard deviation in each experiment was found to be less than $0.5 \%$ as summarized in Table 1. Figure 3 shows the changes in tritium concentration in the water samples as the function of stirring time from each experiment. The tritium concentration in each experiment was within this standard deviation as shown in Fig. 3. These results suggested that the batch treatment method has negligible effects on the tritium measurement. 


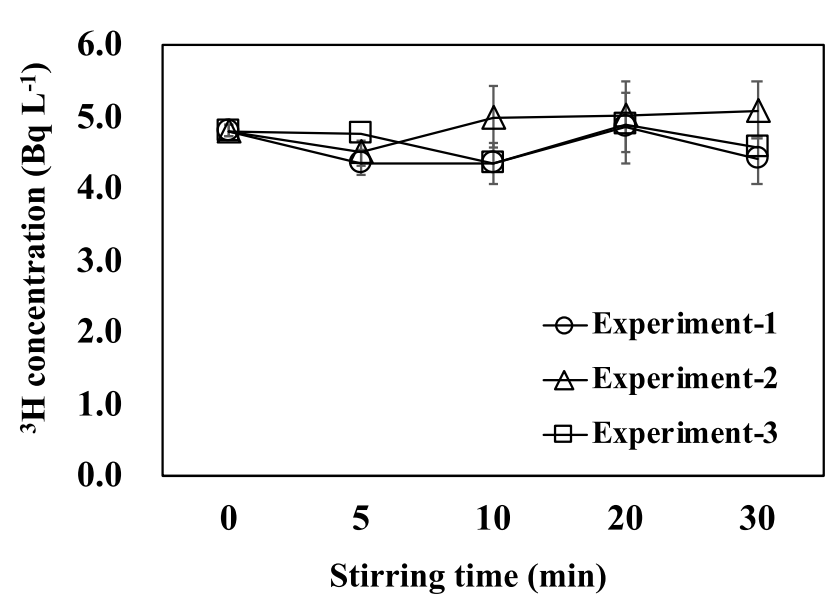

Fig. 3 Change in tritium concentration with respect to stirring time in the water samples from each experiment.

\subsection{Ion concentration in water sample}

Table 1 summarizes the results of ion concentrations for the samples. The yield rates of the dissolved ions were calculated from the ratios of their concentrations before and after stirring. In the batch treatment method, the ion concentrations were decreased in proportion to the amounts of ion exchange resins; however, the changes in the ion concentrations with increased stirring times were small. In Experiment-3, the yield rate of the dissolved ions exceeded $90 \%$ after 5 min of stirring and tended to increase slowly thereafter. Hence, these results suggest that batch treatment can remove dissolved ions as well as the distillation method.

\subsection{Total organic carbon analysis and UV absorbance measurement}

Figure 4 shows the changes in TOC in the water samples as the function of stirring time from each experiment. The TOC in the samples tended to decrease in proportion to the amount of activated carbon and it was confirmed that the removal of impurities such as organic matter (Fig. 4). However, after 10 to 30 min of stirring time in Experiment3 , TOC tended to increase. It is presumed that activated carbon produces the effects of crushed materials.

Figure 5 shows the absorption spectra in the UV range of water samples from each experiment. The measurement of UV absorbance is considered an effective method for investigating organic contamination in water [7]. The absorbance from 230 to $280 \mathrm{~nm}$ corresponds to the absorption band of organic compounds in the UV region. Therefore, we measured the absorption spectra in the UV range from 230 to $280 \mathrm{~nm}$ to confirm whether any organic matter was present in the collected water. In the distillation method, a strong peak due to the absorption of benzyl alcohol was observed at $280 \mathrm{~nm}$; however, a weak absorption was observed using the batch method compared to the distillation method (Fig. 5). Moreover, the batch method has the advantage, which is shorter time than the distillation method.

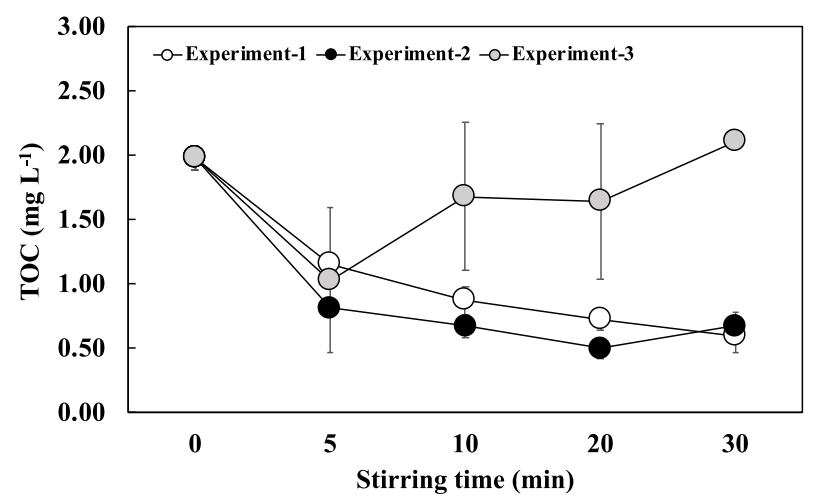

Fig. 4 Changes in TOC with respect to stirring time in the water samples in each experiment.

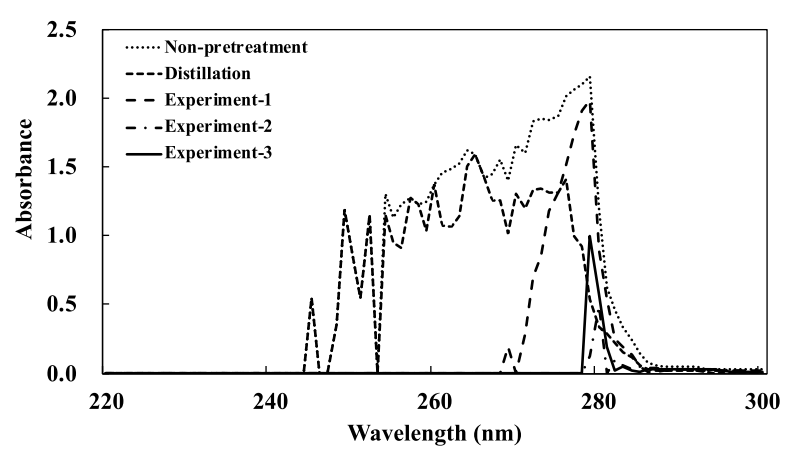

Fig. 5 Absorption spectra in the UV range of water samples in each experiment (stirring time; $5 \mathrm{~min}$ ).

\section{Summary}

From the results of the $\mathrm{EC}, \mathrm{pH}$, tritium concentration, ion concentration and TOC measurements, we confirmed that the pretreatment method involving ion exchange resins and activated carbon successfully removed the impurities in the sample water. Moreover, we confirmed that such an effect can be achieved within a short time (i.e., $5 \mathrm{~min}$ ). Additionally, these results suggested that the batch method has been found to have negligible effects on the tritium measurement. The batch method has the advantage of short-time in comparison with the distillation method. These results demonstrate the effectiveness of the ion exchange resins and activated carbon in removing impurities from the water samples and confirm that effective impurity removal can be achieved over $5 \mathrm{~min}$. In the future, the method is applied to the pretreatment of tritium analysis in environmental water samples (e.g., river water and precipitation) and the analysis of tissue free water tritium and organically bound tritium. This study makes a valuable contribution toward developing processes for analyzing multiple samples of contaminated water (i.e., water contaminating tritium) at the same time by consuming less reagents and space. 


\section{Acknowledgments}

This work was performed with the support and under the auspices of the NIFS Collaboration Research Program (NIFS18KOCA003).

[1] B.J. Teegarden, J. Geophys. Res. 72, 4863 (1967).

[2] H. Morishima et al., J. Radiat. Res. 26, 283 (1985).
[3] UNSCEAR, Sources and Effects of Ionizing Radiation UNSCEAR 2008 Report to the General Assembly with Scientific Annexes (1) (2010).

[4] MEXT, Radioactivity Measurement, Series No.9 (2002).

[5] S. Yokoyama et al., Plasma Fusion Res. 14, 3405099 (2019).

[6] S. Nakasone et al., Plasma Fusion Res. 15, 2405027 (2020).

[7] Y. Takashima, Radioisotopes 40, 520 (1991). 